\title{
EM TORNO DA CIVILIZAÇÃO LUSO-TROPICAL: a contribuição de Gilberto Freyre à sociologia da imigração no Brasil ${ }^{1}$
}

\author{
Márcio de Oliveira *
}

\begin{abstract}
Rigorosamente, não há uma sociologia da imigração na obra de Gilberto Freyre. Contudo o fenômeno da imigração não está ausente das análises sobre o modelo freyriano de amálgama e sobre os processos de miscigenação social e racial. Está presente ainda em conferências e livros sobre a civilização luso-tropical, em seu interesse e viagens por outras culturas e países. Ele pode ser observado ainda em sua atuação parlamentar em defesa da lusofonia durante a Assembleia Constituinte de 1946. Esse paper discute a contribuição de Freyre à sociologia da imigração no Brasil, em relação à discussão mais geral sobre o luso-tropicalismo. Colocando em perspectiva comparada as definições sobre o luso-tropicalismo e as análises dos processos de assimilação, conclui-se que os estudos nos quais Freyre analisa aspectos da imigração foram contrapartida decisiva para o desenvolvimento de suas ideias sobre a civilização luso-tropical, além de constituírem importantes contribuições para a sociologia da imigração no Brasil.

Palavras-chave: Gilberto Freyre. Sociologia da imigração. Imigração. Assimilação. Civilização luso-tropical.
\end{abstract}

\section{INTRODUÇÃO}

Gilberto Freyre (1900-1987) tratou do fenômeno da imigração em momentos distintos de sua obra. Fez menções ao estrangeiro em A história de um engenheiro francês no Brasil (1941), Ingleses no Brasil (1948) e O Brasil em face das Áfricas negra e mestiça (1962), ou ainda em $O$ Brasileiro entre outros hispanos (1975). Em sua atuação política, como deputado eleito pela União Democrática Nacional (pelo estado de Pernambuco), defendeu os direitos dos naturalizados e propôs a transnacionalidade afro-luso-brasileira, como projeto de lei à Constituição de 1946. Enfim, em diversos livros e conferências sobre a civilização luso-tropical, são recorrentes as passagens dedicadas à questão imigrante e às práticas assimiladoras (biológicas e culturais) luso-brasileiras.

Do mesmo modo, Freyre se viu às voltas (por vezes, às turras) com o fenômeno da imi-

* Universidade Federal do Paraná. Departamento de Sociologia.

Rua General Carneiro, 460. Centro. Cep: 80060-150. Curitiba - Paraná - Brasil. marciodeoliveira62@gmail.com

${ }^{1}$ Registro aqui meu agradecimento à leitura cuidadosa e propositiva dos pareceristas indicados pela revista. gração em momentos históricos particularmente delicados. No período do entreguerras, em $O$ mundo que o português criou (1940), ${ }^{2}$ estendeu a hipótese, desenvolvida em Casa Grande $\mathcal{\sigma}$ Senzala, sobre as consequências vantajosas dos imigrantes portugueses em relação aos europeus "puros, dólico-louros" - a ausência de preconceito e plasticidade - nas sociedades coloniais portuguesas. Antes mesmo disso, em Sobrados e Mucambos, Freyre (1968b, p. 344, tomo 1) havia abordado tanto a "assimilação da técnica do europeu [...] pelo mulato da terra" quanto analisado a "sistemática da miscigenação no Brasil”, prevendo, então, a "penetração da cultura brasileira por elementos de origem italiana, germânica, polonesa e síria” (Freyre, 1968b, p. 658, tomo 2). Em Região e Tradição (originalmente de 1941), ${ }^{3}$ ao abordar o impacto da abolição, Freyre analisou a substituição dos escravos por colonos imigrantes nas fazendas de São Paulo. Em um tour de force explícito,

2 Temos aqui a reunião, em livro, de conferências realizadas no Kings College (Londres) e nas universidades de Lisboa, Coimbra e Porto em 1937. Para a edição de 1940, as conferências foram revistas pelo autor.

${ }^{3}$ Esse livro é a compilação de vários artigos publicados entre os anos de 1910 e 1930. 
referiu-se ao papel regionalmente diferenciado dos imigrantes na formação da cultura nacional, ao dizer que o Nordeste, em consequência da "desvantagem" de não ter recebido os novos imigrantes, tornou-se "refúgio da alma do Brasil" (Freyre, $1968,{ }^{4}$ p. 197-198). ${ }^{5}$

Os processos sociais de integração e de miscigenação, comumente relacionados à sociologia da imigração, estão presentes em livros como Ordem e Progresso (1959) e O luso e o trópico (1961). Da mesma forma, Freyre publicou, em 1971, Nós e a Europa Germânica: em torno de alguns aspectos das relações do Brasil com a cultura germânica no decorrer do século XIX, quando retornou ao tema da cultura e da imigração alemã no Brasil, assunto que já havia abordado 31 anos antes em Uma cultura ameaçada: a luso-brasileira (1940). ${ }^{6}$ Finalmente, em Novo Mundo nos Trópicos (1972), afirmou, sem ambiguidade, que a assimilação do outro era característica principal da sociedade brasileira, assumindo como fundamentais os processos sociais clássicos presentes em sociedades imigrantistas.

Não obstante as evidências acima, a questão da imigração parece secundária na vida e na obra freyriana. Dentre seus intérpretes, reunidos por Kominsky, Lépine e Peixoto (2003), apenas Seyferth dedicou espaço à questão. No capítulo intitulado "Nacionaثิ Ф્థ Freyre”, contudo, a questão da imigração não é central, mas secundária, tendo sido analisada œ aí no âmbito do tema maior da nacionalidade

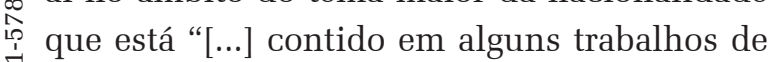
Gilberto Freyre e sua contraposição com ideoi. logias e identidades étnicas avessas à assimi¿ lação e miscigenação [...]" (Seyferth, 2003, p.

$>{ }^{4}$ Para efeitos deste trabalho, utilizamos a segunda edição tesse livro, publicada em 1968. A passagem encontra-se no capítulo "Aspectos de um século de transição no Nordeste do Brasil", publicado originalmente em 1926.

5 ${ }^{5}$ De forma paradoxal, sobretudo para alguém que assinalou a migração da cultura portuguesa para o Brasil, o nordestino foi ali descrito com cores carregadas do sedentarismo dos engenhos.

${ }^{6}$ As datas entre parênteses indicam o ano em que as referidas obras foram publicadas originalmente.
155). Em outro trabalho, agora dedicado à contribuição das ciências sociais brasileiras ao fenômeno da imigração, Seyferth (2004) aparentemente concorda com a tese da inexistência de uma sociologia da imigração na obra de Gilberto Freyre, da qual cita apenas dois trabalhos

- Uma cultura ameaçada: a luso-brasileira e Região e tradição -, não estabelecendo, nesse texto, relações entre a dimensão assimilacionista e miscigenadora das práticas sociais no Brasil com os processos sociais de igual monta, típicos de sociedades imigrantistas. Já no trabalho sobre o caráter multidisciplinar dos estudos da imigração no Brasil, Seyferth (2007) não faz nenhuma referência à contribuição de Freyre. Além disso, não há referências teóricas aos conceitos clássicos da sociologia da imigração, tais como assimilação, ${ }^{7}$ aculturação ou integração ${ }^{8}$ no livro dedicado à sociologia como ciência (Sociologia: introdução ao estudo dos seus princípios, de 1945). Em conclusão, não há razões para se falar em um Freyre, sociólogo da imigração, porém, como demonstro, o mestre pernambucano analisou processos de assimilação e fez referências ao fenômeno da imigração a partir de situações empíricas bem específicas, o que nos coloca diante do seguinte paradoxo.

De um lado, temos a importância conferida aos processos de miscigenação, aos contatos inter-raciais e à civilização de tipo transnacional e, de outro, o fato de o autor não ter dedicado trabalho específico à imigração, mormente quando se sabe que pensou relacional e globalmente a sociedade brasileira. Além disso, o período que Freyre passou nos Estados Unidos e suas constantes referências ao culturalismo de Franz Boas ou ao trabalho de William Thomas e Florian Zaniecki (sobre o

${ }^{7} \mathrm{O}$ conceito de assimilação foi, contudo, assunto de uma entrevista, como é analisado abaixo.

${ }^{8}$ Assinalo, contudo, que o conceito de integracão está presente no título de diversas conferências proferidas após a publicação desse livro, como, por exemplo, "Integração de raças autóctones e de culturas diferentes da europeia na comunidade luso-tropical: aspectos gerais de um processo" (inserida em O luso e o trópico, 1961), onde está, inclusive, definido. 
qual retornamos) sugerem familiaridade tanto com o tema da interpenetração cultural quando com aquele da imigração. Por que, então, não estendeu essa preocupação e conhecimento ao Brasil, dedicando à imigração brasileira estudo específico? O presente artigo retoma essa questão, demostrando que o fenômeno da imigração é efetivamente importante na obra de Freyre, em especial (embora não apenas) quando relacionado às análises que fez sobre a civilização luso-tropical. Para isso, analisamos os trabalhos Uma cultura ameaçada: a luso-brasileira (1980b) e Nós e a Europa Germânica: em torno de alguns aspectos das relações do Brasil com a cultura germânica no decorrer do século XIX (1987). Além desses trabalhos, analisamos os discursos pronunciados durante a Assembleia Constituinte de 1946 e os livros ou conferências $O$ mundo que o português criou: aspectos das relações sociais e de cultura do Brasil com Portugal e as colónias portuguesas (1940), Região e Tradição (1968a), Integração Portuguesa nos Trópicos (1966), Uma política transnacional de cultura para o Brasil de hoje (1960) e O Luso e o Trópico (1961). Como demonstramos a seguir, nesses trabalhos, há passagens e referências sobre o tema da imigração, em especial sobre o caráter assimilador e assimilado do português, que são essenciais ao desenvolvimento das análises sobre o luso-tropicalismo e constituem importante contribuição à sociologia da imigração no Brasil.

\section{A CULTURA AMEAÇADA E A EU- ROPA GERMÂNICA}

O título da conferência pronunciada por Freyre, "Uma cultura ameaçada: a luso-brasileira", ${ }^{9}$ faz pensar que, naquele ano de 1940, pouco depois de iniciada a Segunda Guerra Mundial, havia uma ameaça militar ao Brasil, Portugal ou mesmo às colônias portuguesas. A conferência havia sido promovida pelo Go-

${ }^{9}$ Conferência pronunciada no Gabinete Português de Leitura, cidade do Recife, no dia 2 de junho de 1940. verno Português, presidida pelo Cônsul Geral de Portugal e, apesar de ter sido realizada no Brasil, foi organizada no âmbito das comemorações do "III Centenário da Fundação de Portugal” (Restauração de 1640). Falar, portanto, em ameaça da cultura luso-tropical no Brasil, justamente o país onde residia a maior colônia portuguesa, diante de membros do governo português, embora pudesse soar exagerado, não era incoerente. Porém, o texto tinha também outro interlocutor: o geólogo e botânico alemão Reinahrd Maack (1892-1969) ${ }^{10}$ e seu artigo, The Germans of South Brazil: a German view (1939), citado por Freyre (1980, p. 61-64) e sobre o qual ele já havia escrito para o jornal O Estado de São Paulo no mês de abril daquele mesmo ano de 1940.

Em seu artigo, Maack (1939) afirma que os cidadãos germânicos residentes no sul do Brasil estariam organizando associações nacional-socialistas no intuito de demonstrar solidariedade ao nazismo. As análises de McCann Jr. (1995), Magalhães (1998) e Lopes (2008) mostram que, efetivamente, Hitler se interessou pelo Cone Sul e fez planos para os descendentes germânicos que aí viviam. Porém até que ponto Freyre estava ciente de tudo isso? O fato é que, citando rapidamente o trabalho de Maack, conferiu grande crédito às suas análises. Estaria realmente ameaçada a cultura luso-brasileira no sul do Brasil. Em trabalho publicado naquele mesmo ano de 1940, no primeiro número da Revista de Imigração e Colonização, ${ }^{11}$ o major Aristóteles de Lima Câmara, embora de postura claramente anti-imigrante, sugere outra interpretação desse mesmo artigo de Maack. Em um pequeno

${ }^{10}$ Viveu desde 1923 em Curitiba, onde faleceu. Trabalhou na Universidade Federal do Paraná e no Museu Paranaense. Foi considerado o "mais paranaense de todos os alemães". Em Curitiba, foi homenageado com o "Bosque Reinhard Maack", fundado em 1989, e com a Rua Reinhard Maack. Ver ainda Oliveira (1996) e o sítio www.reinhard-maack.de

${ }^{11}$ A revista circulou entre 1940 e 1955 em quatro números por ano, com exceção dos anos 1950 e 1952, nos quais publicou apenas dois números, e 1955, em que publicou apenas um número. Foi editada pelo Conselho de Colonização e Imigração (Decreto 406, de 4 de maio de1938), subordinado à Presidência da República, cuja função era gerir a política imigratória brasileira. 
artigo intitulado "Os alemães no Sul do Brasil (ponto de vista brasileiro)", ${ }^{12}$ Câmara (1940, p. 33) afirma que a análise de Maack errava ao ligar os alemães e descendentes que vivem no sul do Brasil ao nazismo: "não há tal”. Ao contrário de Freyre, Câmara afirma que não havia nem mesmo problemas de integração. Para provar sua afirmação, reproduziu uma carta com o pedido de cidadania brasileira que "centenas de estrangeiros" endereçaram às autoridades (Câmara, 1940, p. 34). Embora reconhecendo certo isolamento e autonomia em algumas colônias, mormente no Vale do Itajaí (estado de Santa Catarina), mostra que alguns descendentes - Lauro Muller e Felipe Schmidt - destacaram-se na vida nacional. Rebatendo pouco a pouco os argumentos de Maack, Câmara concluiu seu artigo citando passagem do próprio Maack, para quem "[...] as gerações mais novas de teuto-brasileiros, sendo cidadãos do Brasil, se entusiasmam grandemente com a ideia de um Brasil maior, e nenhuma acusação pode ser mais injusta que a de lhes atribuir ideias de separatismo" (Câmara, 1940, p. 43).

Em novo artigo, publicado na citada Revista de Imigração e Colonização e escrito conjuntamente com o engenheiro e bacharel em Direito Arthur Hehl Neiva (1909-1969), após viagem que ambos realizaram a diversas colônias de imigrantes (alemãs e japonesas) సิ localizadas nas regiões sudeste e sul do Braષ્ sil, Câmara e Neiva (1941) apresentam uma i radiografia da realidade encontrada. Afirmam, क inicialmente, que, devido ao histórico descaso dos governos brasileiros, havia claros elemeni⿱ tos desnacionalizadores, como o lar, a escola, $\stackrel{2}{a}$ a igreja e as associações. ${ }^{13}$ Resistir à perda da ¿ identidade havia se tornado uma prática legíè tima e necessária. Além disso, tanto as inicia-

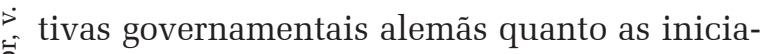
tivas de religiosos alemães haviam construído

${ }^{12}$ A expressão "ponto de vista brasileiro" é uma inequívoca resposta ao artigo de Maack, que traz, em seu subtítulo, a expressão "A german point of view".

${ }^{13}$ Para uma análise detalhada do relatório de Câmara e Neiva e das ações de religiosos alemães no sul do Brasil, ver Schulze (2014, p. 115-138). uma imagem positiva dos imigrantes e, em sentido contrário, negativa dos brasileiros, embora essas não necessariamente atentassem ou ameaçassem a soberania nacional. Apesar disso, os autores, "dada a gravidade do momento internacional” (ou seja, antevéspera da Segunda Guerra Mundial), propõem ações de nacionalização, cujo objetivo seria “ fazê-los amar e respeitar o Brasil [...] sem que sejam feridos os interesses econômicos dessas zonas" (Câmara; Neiva, 1941, p. 107-108). O problema era tão somente adaptá-los "ao meio nacional" ${ }^{14}$

Seyferth (2004, p. 8) estranha que um autor "[...] assumidamente pluralista, como Gilberto Freyre, tenha condenado o germanismo do Sul em nome da unidade nacional". Nos círculos imigrantes germânicos, não era incomum manter-se próximo da cultura alemã, advogando a justeza da identidade teuto-brasileira. Isso não implicava, porém, recusar-se à assimilação ou à nacionalização. Contudo, naquele contexto dos anos anteriores à Segunda Guerra Mundial, estava difundido o temor em relação à integridade do território brasileiro, ${ }^{15}$ fato que apenas legitimava as ideias contidas na conferência. Não há evidências que demonstrem o conhecimento de Freyre sobre os trabalhos de Câmara e (ou) de Arthur Neiva, ${ }^{16}$ nem mesmo sobre os planos nazistas para o Brasil. Seyferth (2003, p. 165) afirma, sem apresentar dados precisos, que esse texto seria uma reação de Freyre aos princípios nazistas. Em uma entrevista ao Diário de Pernambuco, quando questionado sobre o que lhe parecia ser a capacidade de assimilação da cultura brasileira, tomando a imigração alemã como referência, Freyre (1942, p. 5) apresenta outro argumento:

A língua alemã falada por colonos alemães no Sul ra-

\footnotetext{
${ }^{14}$ Essas ações seriam finalmente organizadas no interior da chamada Campanha de Nacionalização, conjunto de decretos publicados entre 1938 e 1940, que visavam à nacionalização compulsória de estrangeiros e à erradicação dos chamados "quistos étnicos". Para maiores detalhes, ver Ribeiro (2012).

${ }^{15}$ Para uma análise sobre a agenda do nazismo para a América do Sul, ver Lopes (2008).

${ }^{16}$ Temos aqui, efetivamente, fatos históricos concomitan-
} tes e não relações histórico-causais. 
pidamente se enche de palavras portuguesas. Velhas festas do catolicismo luso-brasileiro como a da laranja, em Santa Catarina, acabam atraindo colonos alemães de formação protestante. Entretanto, esse poder de assimilação correrá o risco de tornar-se de todo ineficiente cada vez que o imigrante se encontre em condições econômicas e higiênicas largamente superiores às do brasileiro velho. Foi para esse ponto que chamei a atenção dos meus amigos do Rio Grande do Sul e de Santa Catharina, inclusive os interventores dos dois Estados que me dão a impressão de administradores atentos aos problemas sociais mais sérios do governo e não apenas aos burocráticos e urbanísticos.

As autoridades precisavam manter-se atentas aos "problemas sociais mais sérios", ou seja, aos impasses que obstruíam "o poder de assimilação” da cultura luso-brasileira, sempre que o colono alemão se encontrasse "em condições econômicas e higiênicas largamente superiores ao brasileiro velho". O temor em relação à não miscigenação entre os grupos imigrantes e o "brasileiro velho" aparece aí relacionado ao desequilíbrio econômico regional entre as áreas imigrantes e "brasileiras". Para setores intelectuais e grupos militares, a relativa homogeneidade étnica das colônias de imigrantes, nos estados do Sul, era conhecida, alardeada, até justificando os decretos nacionalizadores (Magalhães, 1998). Mas, ao fim e ao cabo, se cuidada fosse a questão econômico-sanitária, Freyre não parece duvidar do sucesso da cultura brasileira em assimilar a cultura alemã ou italiana. Por isso a ameaça apresentada na conferência, pronunciada dois anos antes da entrevista talvez se explique tanto pelo contexto bélico de então quanto pela comemoração do III ${ }^{\circ}$ Centenário da Restauração.

Em relação às ideias de Freyre sobre a colonização alemã, deve-se lembrar de que o impasse no citado "poder de assimilação" da cultura luso-brasileira no sul do país já havia sido apontado em artigos publicados no Diário de Pernambuco durante o ano de 1939, posteriormente republicados no citado capítulo (Narcisismo gaúcho), em formato aparentemente condensado. Vale assinalar, porém, que o conhecimento de Freyre sobre o Rio Grande do Sul não foi resultado de ampla pesquisa. Como afirma Silveira ([200-]), Freyre não dedicou "mais do que alguns ensaios ao Rio Grande do Sul". Dois deles parecem ter sido frutos de viagens consecutivas, realizadas em 1939 e 1940, a primeira delas a convite do interventor do estado do Rio Grande do Sul, Cordeiro de Farias, no exato momento da deflagração da citada Campanha de Nacionalização. Segundo Nedel (2007, p. 86), o interesse político dos gaúchos com esse convite era "[...] se fazerem representar, a qualquer preço, dentro de limites luso-brasileiros.” Esse desejo se ajustava como uma luva às ideias que o próprio Freyre desenvolveria não apenas nos artigos "gaúchos", mas também em sua tese sobre o luso-tropicalismo. ${ }^{17}$ No primeiro dos artigos, Narcisismo gaúcho, Freyre demonstra inequívoco apreço pela singularidade gaúcha. Porém, ao analisar os processos de assimilação entre as populações antigas e as imigrantes, é relativamente ambíguo. Ora afirma que os adventícios se assimilavam ao peso da cultura dos "donos da terra", ora diz que a falta de "poder de assimilação” estava no "...desequilíbrio entre condições de vida das duas populações - a tradicionalmente brasileira, e a neobrasileira [...]" (Freyre, 1968a, p. 250). O desequilíbrio em questão era rodoviário - falta de estradas -, mas também de assistência sanitária e social. A insuficiente malha rodoviária produziria isolamento. Se acaso esse "desequilíbrio" se acentuasse, "antropologistas ligeiros e sociólogos ainda mais levianos" poderiam interpretar as distâncias socioeconômicas entre as duas populações como uma superioridade "eugênica" das ditas "raças puras" (Freyre, 1968a, p. 250). Tem-se aí uma clara análise de processos de assimilação em realidade marcada por forte contingente imigrante. Contudo, desse momento do texto em diante, Freyre muda o registro e analisa o carnaval aí praticado. Apresenta, então, aque-

${ }^{17}$ Palhares-Burke (2005) inventariou com maestria as influências intelectuais de Freyre, tanto brasileiras quanto estrangeiras. E interessante pensar também na importância das influências fortuitas (frutos de viagens, encontros etc.), muito embora essas últimas sejam seguramente muito mais dificilmente avaliáveis. 
las características regionais "genuínas" que ele via em risco de descaracterização no âmbito de processos nacionalizadores, fato semelhante àquele encontrado no carnaval da "Praça Quinze" (Rio de Janeiro). Como compreender o final do texto? O fenômeno da imigração não valeria como tal, mas apenas como antessala ao resgate do tema da regionalidade?

O segundo artigo sobre o Rio Grande, intitulado "Sugestões para o Estudo Histórico e Social do Sobrado no Rio Grande do Sul”, deveu-se à segunda viagem ao estado, em 1940, e possibilitou ao autor apresentar ideias para o estudo do sobrado gaúcho. ${ }^{18}$ Além disso, nessa segunda viagem, Freyre proferiu, durante o III Congresso de História e Geografia, ${ }^{19}$ a conferência "Continente e Ilha", quando retomou suas ideias sobre a assimilação dos imigrantes no sul do Brasil. Após fazer referências às "ilhas de colonização", ou seja, às cidades, Freyre (1943, p. 27-28) afirma que o "sentido de continente", ou seja, de unidade, deveria prevalecer sobre os "excessos da ilha" sem, contudo, abafá-las. Referindo-se a Porto Alegre e à cultura gaúcha, assim se exprime:

Que se sintam aqui, como em nenhuma outra cidade grande do Brasil, o gaúcho, no pitoresco como no essencial de sua cultura, inclusive culinária; o missioneiro; a influência chamada indistintamente castelhana; a influência dessas duas ricas culturas

¿ ${ }^{18}$ É possível aqui traçar um paralelo entre a análise do - sobrado gaúcho e aquela realizada sobre a "re-europeização" que representou a introdução do sobrado no espaço

$>$ urbano no início do século XIX, fruto da abertura dos por-

ô tos e da chegada de novos europeus às principais cidades

brasileiras. Tanto naquele momento quanto no início do

século XX, o sobrado apresentava-se como forma híbrida,

s que misturava as novas formas arquitetônicas europeias

Fi (fruto da imigração então recente) com as antigas habitações portuguesas.

${ }^{19}$ Segundo consta na edição de 1943, quando foi publicada, a "conferência foi lida no Salão de Conferências da Biblioteca do estado do Rio Grande do Sul, no dia 19 de novembro de 1940" (Freyre, 1943). neobrasileiros (Freyre, 1943, p. 53, grifo do autor).

Nesse ano de 1940, Freyre apresenta argumentos próximos do multiculturalismo atual, oscilando entre a importância da regionalidade e da nacionalidade, embora sempre em proveito do projeto luso-brasileiro. A comparação das análises do gaúcho com aquelas dedicadas ao nordestino é ilustrativa. Em Região e Tradição, no capítulo dedicado ao narcisismo gaúcho, Freyre (1968a) defende, sem citar referência alguma, a mesma tese já apresentada na conferência "Continente e Ilha": o "gaúcho atual” seria um elemento híbrido, consequência da assimilação dos imigrantes alemães e italianos (Freyre, 1968a, p. 243). O nordestino, por sua vez, é descrito como avesso ao nomadismo, e "estranhamente sensível às suas raízes” (Freyre, 1968a, p. 128). Numa palavra, nada seria mais oposto à mobilidade conceitual do migrante do que o nordestino, exemplo inverso do gaúcho, novamente definido como neobrasileiro.

Freyre realizaria ainda outras viagens ao Rio Grande do Sul até o ano de 1969. Além desses contatos e escritos, ofereceu-se, no que foi atendido, a fazer o prefácio da obra "A contribuição teuta à formação da nação brasileira”. ${ }^{20}$ Apesar disso e de ter sido convidado a presi$\operatorname{dir}^{21}$ o I ${ }^{0}$ Colóquio de Estudos Teuto-Brasileiros em 1963, aí não compareceu, tendo apenas enviado seu discurso. Finalmente, no livro Nós e a Europa Germânica: Em torno de alguns aspectos das relações do Brasil com a cultura germânica no decorrer do século XIX (Freyre, 1987), retorna ao tema com outro teor, ao reunir ali um conjunto de ensaios, inéditos na sua maioria. Falando sobre a presença germânica no Brasil como um todo, logo na "Introdução", Freyre (1987, p. 33-34) adverte o leitor:

Nos meados do século XIX, a cultura da Europa

${ }^{20}$ No prefácio dessa obra, afirma o contrário, ou seja, que foi convidado, no que é corrigido em nota de rodapé pelo próprio autor, Oberacker Jr.

${ }^{21}$ De fato, foi o "presidente de honra" do colóquio. O convite teria sido uma forma de agradecer a Freyre sua sugestão para a realização do colóquio. 
germânica projetou-se sobre o Brasil meridional de modo, sob alguns aspectos, considerável; mas sem que deixasse aquela Europa de receber do Brasil produtor de tabaco, de café de cacau, de excelentes madeiras de marcenaria - influências que lhe modificariam hábitos e que lhe inspirariam novas perspectivas do trópico e até novos modos de artistas de tratarem o material, das suas respectivas artes, de origem brasileira.

Freyre opõe aí, sem nuances, dois blocos culturais. A cultura brasileira não se deixa dominar, antes influencia. Nesse livro, não há análise de processos reais de interação, mas apenas comentários gerais sobre as contribuições positivas do imigrante alemão - "colaborador valioso", diz Freyre -, trazidas para uma cultura brasileira considerada como consolidada de norte a sul do país. Não obstante a apologia tradicional da cultura brasileira, Freyre incita o leitor ao estudo de personagens históricos, como a milionária Elizaberth Lundgren, ou literários, como a "fraulein governante" de Mário de Andrade, em Amar verbo intransitivo. Cita ainda o Meyer do livro Inocência, além de outros personagens que eram objeto de estudo nos "Colóquios de Estudos Teuto-brasileiros", organizados na cidade de Porto Alegre.

Dos nove capítulos que compõem o livro, quatro são dedicados aos contatos de Pernambuco com a "Europa germânica". No capítulo sobre Graça Aranha - "um germanizado que se desgermanizou”, Freyre tenta compreender as origens da posição germanista do escritor. No capítulo sobre o historiador Alfredo de Carvalho, a análise recai sobre as influências germânicas e suas consequências. Mesclados às impressões subjetivas de sua infância na cidade de Recife, os exemplos se repetem. É o estilo ensaístico do autor, recheado de referências ora históricas, ora literárias. De uma forma geral, contudo, são análises particulares sobre aspectos mais particulares ainda, em evidente descompasso com os temores da “cultura ameaçada” de 1940.

No II $^{\circ}$ Colóquio de Estudos Teuto-brasileiros, Freyre volta a fazer novas referências à cultura e à imigração alemã no Brasil. Dessa última feita, porém, já em 1974, tratou apenas de abrir esse segundo colóquio, realizado em Recife, fazendo referências a ilustres alemães, germanófilos brasileiros e obras literárias cujo assunto geral era a imigração ou a cultura alemã no Brasil. Concluiu sua conferência inaugural de forma positiva, enfatizando o novo campo de estudos que se abria cada vez mais: "O elemento alemão na formação cultural do Brasil continua, sob vários aspectos, assunto virgem para sociólogos brasileiros da Cultura, da Arte, das Letras. É assunto magnífico" (Freyre, 1974, p. 11).

Finalmente, em 1980, no prefácio da $2^{\mathrm{a}}$ edição de Uma cultura ameaçada: a luso-brasileira, Freyre surpreendeu ao apresentar o livro como um "clamor filosófico". Defendeu a "resistência" da cultura luso-brasileira ao "imperialismo cultural, representado por cultura centro-europeia, na qual se encarnaram valores e desígnios opostos aos social e culturalmente luso-brasileiros" (Freyre, 1980b, p. 16). Da ameaça nazista de 1940, passando, contudo, pelas positivas contribuições germânicas dos anos 1970, em 1980 a cultura luso-brasileira voltava a ser objeto de genéricas ameaças estrangeiras, então relacionadas ao imperialismo europeu.

Se a imigração alemã ora contribuía, ora ameaçava, o mesmo não pode ser dito da imigração italiana. As referências a essa imigração estão em Ordem e Progresso (1962). ${ }^{22}$ Demograficamente, os italianos foram o grupo mais importante na virada dos séculos XIX ao XX, como bem notou Freyre (1962). Diferenciando claramente os dois grupos de imigrantes (alemães e italianos), Freyre afirma que a imigração italiana havia sido particularmente importante e bem-vinda, porque havia barrado, em parte, a influência germânica e reforçado o caráter

${ }^{22}$ Oliveira (2003) afirma que, nesse livro, Freyre continua a desenvolver a tese da desagregação da sociedade patriarcal brasileira e, embora traga novidades, como o uso da história oral, inscreve-se no quadro maior do debate sobre modernidade e tradição que marcou o final dos anos 1950 e início dos anos 1960. 
[...] latino e católico, em particular, da civilização que aqui vinha se desenvolvendo, de certo modo ameaçadas pela presença alemã tanto no Rio Grande do Sul e em Santa Catarina, como em São Paulo e no Espírito Santo. Verificou-se esse reforço étnico-cultural em período agudo de desapreço, da parte do brasileiro médio, pelas suas origens hispano-católicas - particularmente luso-católicas - sob a sedução de evidências de superioridade técnica de anglo-saxões e alemães, predominantemente protestantes: superioridade interpretada pela gente simplista de então, até na França, como absoluta ou total (Freyre, 1962, p. 335).

A imigração italiana, também ela, tem valor relacional e funcional: é positivamente avaliada porque, sendo latina, se opunha "às seduções de superioridade” de anglo-saxões e germânicos. Reconhece-se, ali, a posição do autor em relação ao fenômeno da imigração: tudo e todos que supostamente reforçavam o padrão luso-brasileiro eram bem-vindos.

Tomando esses trabalhos em seu conjunto, pode-se afirmar a existência de uma sociologia da imigração na obra de Gilberto Freyre? Rigorosamente falando, não. Segundo Seyferth (2000), o projeto regionalista é mais importante do que a questão migratória em Freyre. Nele, a preocupação central era a nacionalização excessiva das manifestações culturais regionais. É possível enquadrar os escritos gaúchos nessa perspectiva, deslocanจิ do-os da temática imigrante stricto sensu. Se¿ gundo Nedel (2007, p. 86), o Rio Grande do Sul serve para Freyre como efeito-demonstração da eficácia do processo colonizador por : capacidade lusa de assimilação das correntes $\therefore$ migratórias europeias. A cultura portuguesa no sul do Brasil, frente aos desafios da grande 今ं imigração para a região, revelaria ainda mais $\therefore$ sua qualidade assimiladora já comprovada no Nordeste. Não obstante a posição das autoras, as contribuições analisadas revelam profundo conhecimento teórico e razoável familiaridade empírica com o tema da imigração. A título de exemplo, não há diferença entre as teses assimilacionistas de Freyre e àquelas defendidas por alguns teóricos de Chicago. Todas elas são, ainda, muito próximas das que estão presentes nas páginas da Revista de Imigração e Colonização. Em termos cronológicos, os escritos de Freyre sobre o fenômeno da imigração acompanham o momento político-institucional do país de 1946 - quando apresentou projetos como deputado constituinte - até 1972, quando publicou O luso e o trópico. Talvez devido à importância dos objetivos práticos perseguidos durante esse período, a contribuição teórica pareça menos relevante. O fundamental, porém, é a ideia principal que Freyre defende constantemente: o fenômeno da imigração não se bastava, antes servia. Funcionava como espécie de trampolim para alcançar outros objetivos. Se quisermos pôr nesses termos, trata-se de uma sociologia da imigração teoricamente robusta, porém limitada a apenas uma questão que, aparentemente, muito incomodava. Seu objetivo era prático e normativo: a imigração alemã poderia ameaçar, caso não fosse controlada. Era bem-vinda, se assimilada. Já a imigração italiana foi positivamente analisada, porque, frente às supostas ameaças germânicas ou superioridades anglo-saxônicas, os italianos revigoravam a cultura lusa nos trópicos.

\section{A IMIGRAÇÃO E A CIVILIZAÇÃO LUSO-TROPICAL}

Os escritos sobre imigração, em Freyre, ganham especial relevo quando confrontados à tese geral da civilização luso-tropical. A compreensão dessa civilização pode ser resumida numa expressão: capacidade de assimilação. Freyre sempre defendeu a tese segundo a qual todos os imigrantes vindos ao Brasil seriam assimilados ao padrão luso-brasileiro. A cultura imigrante ou o próprio imigrante seria, assim, apenas um elo a mais na eterna expansão do mundo criado pelo português. Em consequência, vale insistir, não havia razões para se interessar, de perto, por qualquer um dos grupos imigrantes, tomando-os isoladamen- 
te. A “ameaça à cultura luso-brasileira”, para além do contexto da Segunda Guerra, pode ser compreendida, em sentido contrário, como a defesa do projeto civilização luso-tropical. Em que momento, porém, teria surgido o luso-tropicalismo? Segundo o próprio Freyre, surgiu durante as diversas conferências proferidas na Europa nos anos 1930, no King's College. O sentido geral delas foi inicialmente sintetizado em $O$ mundo que o português criou (1940). Segundo o próprio autor, após sua criação, a expressão teria sido discutida por diversos especialistas. Foi retomada em diversas outras conferências ainda na década 1950, em particular na conferência "Uma cultura moderna: a luso-tropical”, proferida em Goa (Índia) em $1951,{ }^{23}$ e em Integração Portuguesa nos Trópicos, publicado originalmente como livro em 1958 (Freyre, 1960, p. 9-36). Exatamente entre o primeiro livro de 1940 e as conferências e livros dos anos 1950, se situa a atuação política de Freyre na Constituinte de 1946.

O objetivo geral dos trabalhos que Freyre dedica à questão - $O$ mundo que o português criou, Aventura e Rotina, Integração portuguesa nos trópicos, Ordem e Progresso, O luso e o trópico e Novo mundo nos trópicos - era compreender a diferença dos métodos da colonização portuguesa daqueles de outros europeus. ${ }^{24}$ Dessa diferença advinha a singularidade da civilização luso-tropical. Seria demasiado resgatar aqui todos os momentos do livro em que Freyre apresenta e (ou) exemplifica sua expressão. Analisando, por exemplo, a "política de assimilação do Português", afirma que ela coincidiu com a "política de catequese da Igreja", como demonstram os "métodos de assimilação recomendados por Gregório I a Santo Agostinho". Mas a particularidade cristã ibérica lentamente afastou os portugueses dos outros europeus, fazendo-os lograr sucesso onde aqueles teriam fracassado. Nesse pequeno li-

${ }^{23}$ Publicado em "Um brasileiro em terras portuguesas”, 1953.

${ }^{24}$ O próprio Freyre (1961, p. 11) afirma que os livros Um brasileiro em terras portuguesas, Aventura e Rotina, Integração portuguesa nos trópicos e o próprio O luso e o trópico foram tentativas de compreender aquela diferença de métodos. vro, que não chega a 100 páginas, encontra-se a tese do português com “... seu passado étnico, ou antes, cultural de povo indefinido entre a Europa e a África”. Como se sabe, Freyre viajou à África apenas ao final de seu mandato na Câmara Federal. Portanto, ainda que seminal, O mundo que o português criou é livro fundamentalmente ensaístico. A título de exemplo, Freyre apresentava, aí, a sociedade brasileira como "um processo de alongamento de uma cultura antiga numa nova" (Freyre, 1940, p. 32). A cultura lusa, no Brasil, tinha mantido, da matriz portuguesa, a citada capacidade de assimilação. É fundamentalmente "transnacional” e apresenta "vigor híbrido" (Freyre, 1940, p. 55). Naquele momento, porém, as evidências empíricas da capacidade assimiladora lusitana tinham como lastro apenas as observações feitas durante a viagem ao Rio Grande do Sul, quando apresentou o processo de "abrasileiramento" dos colonos europeus.

No extremo sul do Brasil, onde acabo de estar em viagem de contato rápido com a gente e a paisagem daquela região neobrasileira, impressionaram-me certas evidências de abrasileiramento, do alemão e de outros colonos, pelo gesto, pelo ritmo de andar, pela prática de atos tradicionalmente brasileiros (Freyre, 1940, p. 33).

Citando Durkheim, acredita Freyre estarmos diante da pressão do social sobre o indivíduo, das práticas brasileiras que lentamente dominavam o cotidiano dos colonos, fenômeno observável no hábito do chimarrão ou na predileção pela goiabada com queijo. Os clássicos conceitos de assimilação ou de aculturação surgem aí subentendidos ainda em outras "evidências de abrasileiramento": "O andar da gente de Blumenau não é mais alemão: já é brasileiro" (Freyre, 1940, p. 36). Fiel ao método desenvolvido, Freyre observa hábitos culturais (formas de andar, culinária, mudanças linguísticas) para reforçar a tese da inevitabilidade do abrasileiramento dos novos imigrantes e seus descendentes. Mas, embora o processo de abrasileiramento estivesse em marcha no final daqueles anos 1930, Freyre acreditava que o processo de 
integração manteria certa pluralidade no seio da civilização luso-brasileira.

E o semialemão se tornará brasileiro e até entusiasta do Brasil. O alemão se integrará na tradição luso-brasileira, sem deixar, é claro, de trazer para essa tradição alguma coisa de novo e dos seus antepassados. O italiano também. E o polonês, o húngaro, o judeu, o japonês, o austríaco, o russo ucraniano, o espanhol, o sírio. Somos o começo de uma vasta cultura plural (Freyre, 1940, p. 36).

Questionado sobre como lidar com essa pluralidade, ou seja, se "devemos nos fechar na nossa cultura tradicional luso-brasileira”, responde evocando a tradicional solidariedade cultural lusa:

Procurando responde-la, é que toquei no ponto que considero de importância capital para o Brasil, das relações da cultura luso-brasileira - que para nós é mais do tradicional: essencial - com as culturas mais novas representadas por grupos numerosos de imigrantes: a alemã, a italiana, a polonesa, a húngara, a austríaca, a japonesa, a israelita.

Não me parece que o Brasil deva fechar-se na sua cultura tradicional. Defendê-la, sim, pois ela é nossa principal condição de vida e de nação. Mas defende-la desenvolvendo-a. Nas páginas que se seguem - páginas em que o ponto de vista não é só cientificamente sociológico, mas às vezes, o normativo e político -, procuro mostrar como é possível defender e desenvolver aquela cultura por meio de uma solidariedade maior do Brasil com Portugal e com as colônias portuguesas (Freyre, 1940, p. 37-38).

A forma de defender a "cultura tradicional” era paradoxal: abrir-se ao mundo português. Nas páginas seguintes, Freyre abandona o ponto de vista "cientificamente sociológico" em prol de posição normativa e política. Era preciso "defender e desenvolver aquela cultura”, ou seja, aquela cultura luso-brasileira, das influências das novas culturas europeias. Era necessário apelar, enfim, para a solidariedade com Portugal e suas colônias.

Ao receber, há cerca de um ano, os membros do Conselho de Imigração e Colonização, o presidente Vargas soube salientar o direito que toca ao Brasil de escolher as correntes imigratórias que mais nos convêm. E também o dever de seguirmos, nessa es- colha, o critério histórico.

O critério histórico é o da formação luso-brasileira. O que for hostil a essa formação é contrário aos interesses essenciais do Brasil (Freyre, 1940, p. 41).

O trecho acima demonstra tanto o envolvimento político do autor com a questão imigrante quanto o fato de que suas análises e seu engajamento estavam longe da dimensão estritamente científica. Revela ainda seu grau de conhecimento tanto dos debates varguistas sobre a política migratória, quanto o lugar - Conselho de Imigração e Colonização - onde ocorriam. Desse momento em diante, sucedem-se diversas intervenções e artigos na imprensa, em particular na revista $O$ Cruzeiro e no jornal Diário de Pernambuco. A defesa pública de determinada política de imigração para o país teria mesmo atraído à atenção do próprio Vargas, que o convidaria, sem sucesso, a presidir o Conselho. Freyre voltaria à questão imigratória durante os trabalhos da Assembleia Constituinte de 1946. Eleito deputado federal (UDN, PE) em dezembro de 1945 , tomou posse na $40^{\mathrm{a}}$ sessão da Assembleia Constituinte, no dia 4 de abril, aí permanecendo até o dia 18 de setembro de 1946, data da promulgação da nova Constituição, cumprindo, então, mandato ordinário até 1950. "Como constituinte apresentou emendas de importância sociológica ao projeto da Constituição, tendo sido responsável pela redação final dos dispositivos à ordem econômica e social e aos direitos dos naturalizados" (Chacon, 1994, p. 25). Lutou ainda contra o preconceito de raças, propôs nova redação ao capítulo sobre a ordem econômica e social e, finalmente, a criação do Instituto Joaquim Nabuco.

A Câmara dos Deputados apresenta em seu sítio, na rubrica "Discursos e notas taquigráficas", 28 discursos do deputado Gilberto Freyre. Em dois deles, há referências diretas à questão imigrante. Em 1949, discursando no centenário de Joaquim Nabuco, faz referência à sua oposição à imigração chinesa. Anos antes, porém, durante os trabalhos da Constituinte, Freyre fez um discurso ("Em torno de um projeto de Constituição”) em que a questão imigratória 
é central. Braga (1998, p. 506-507) afirma que se trata de seu discurso mais longo, 20 páginas, cujo teor central girou em torno de duas questões: a assimilação do imigrante e o status jurídico do português. Propondo a supressão parcial do § 16 do art. 164, Capítulo III, Título V, Freyre (apud Chacon, 1994, p. 83) afirma:

Diz-se aí: 'A entrada de imigrantes estará condicionada à sua capacidade física e civil, assim como à garantia de sua assimilação'. É evidente que a assimilação de imigrantes escapa a qualquer garantia por antecipação, podendo quando muito prever-se, por ocasião da entrada de imigrantes, que os de certa procedência venham a ser assimilados mais fácil e rapidamente pelo meio brasileiro, que os de outra origem $^{25}$. Garantir antecipadamente essa assimilação é que ninguém pode. Proponho, assim, que se suprima no referido §16 art. 164, Capítulo III, Título V 'assim como à garantia de sua assimilação'.

Creio que a Constituição pode consagrar, na parte referente à imigração ou à naturalização, é a situação especial do português no Brasil. Como já salientou em lúcido discurso nesta Assembleia o ilustre deputado por São Paulo Sr. Aureliano Leite, para os brasileiros, os portugueses não são estrangeiros: são portugueses. Esta é a realidade sociológica que cabe à Constituição consagrar e confirmar, no interesse do desenvolvimento das relações entre o Brasil, Portugal e as comunidades neoportuguesas da África, da Ásia e das Ilhas: comunidades que a cada dia constituem um bloco transnacional mais forte, de cultura e de população orientadas por tradições e destinos comuns e servidas pela mesma língua, também transnacional ou sobrenacional, e por isso mesmo, nem nacionalmente portuguesa nem nacionalmente brasileira, mas sobrenacionalmente portuguesa. ${ }^{26}$

O discurso inscreveu-se na grande discussão sobre a condição do estrangeiro, sobre as condições para aquisição da nacionalidade brasileira e sobre a política de imigração. A presença de Freyre aí não é, portanto, fortuita e está alinhada com suas preocupações sobre a presença imigrante no Brasil e sobre a supremacia da matriz lusófona. O conhecimento sobre os

${ }^{25}$ Essa análise permite afirmar que a ausência do conceito de assimilação no livro Sociologia (1945) não se deve a qualquer desconhecimento da teoria.

${ }^{26}$ Na redação final, no artigo 162, dedicado "à seleção, entrada, fixação e distribuição dos imigrantes", consta, finalmente, um único parágrafo sem a menção "à garantia de assimilação". processos de assimilação ("escapa a qualquer garantia por antecipação") e de sua importância social permite que Freyre proponha a supressão dessa exigência. Na continuação do discurso, encontra-se a afirmação mais instigante: "os portugueses não são estrangeiros, são portugueses”. Freyre não duvida da singularidade do português frente aos outros estrangeiros. Como prova disso, diferencia, dentre os processos de assimilação, aqueles decorrentes do contato entre povos (indivíduos) decorrentes de civilizações distintas e aqueles oriundos de uma mesma civilização ${ }^{27}$. Por isso, caberia à Constituição reconhecer e promover essa "realidade sociológica”. A principal ação seria, assim, "preparar-se" para que os novos imigrantes não modificassem a "origem predominantemente lusitana”. Contudo, isso não deveria ser feito separando "brasileiros natos" dos "neobrasileiros", para depois "nos queixar [que] resistem à assimilação". Por isso, "no interesse da nacionalidade", havia a necessidade do "reconhecimento da situação especial do português em nosso meio" (Freyre apud Chacon, 1994, p. 83-86).

O final da passagem acima (e não do discurso, que se estende por mais 10 páginas) não surpreende. Freyre advoga, primeiro, a tese da transnacionalidade (ou "sobrenacionalidade") portuguesa. Como parâmetro da imaginada adaptabilidade (ou supremacia) portuguesa em qualquer região do Brasil, cita artigo em que é analisado o comportamento de portugueses no clima frio dos Estados Unidos. Conclui defendendo a eliminação de dispositivo que limitava aos brasileiros natos a revalidação de diplomas de universidades estrangeiras. Mendes (2014) afirma que está aí, em matriz, o "conceito sociojurídico de transnacionalidade afro-luso-brasileira", talvez o embrião da atual Comunidade dos Países de Língua Portuguesa.

A tese da luso-tropicalidade seria efetivamente desenvolvida após a viagem à África, quando Freyre publica Aventura e Rotina

${ }^{27}$ Freyre aparentemente desconhecia os sentimentos antilusitanos tão comuns na cidade do Rio de Janeiro no início do século XX. Ver Ribeiro (1987). 
(1980), retomando o "manifesto político", esboçado em $O$ mundo que o português criou, de exaltação do colonialismo português, do qual seria, à tort et à raison, defensor. A plástica cultura lusa ganharia contornos claros e não se limitaria a incorporar aqueles que, porventura, com ela entram em contato. Iria ao encalço do outro para nele se fundir, para unificar toda diversidade, o “... Português, criando um novo mundo não só na América, como na Ásia, na África e até na Oceania, fez desse mundo, sob todos os aspectos, uma combinação de diversidade com unidade" (Freyre, 1980, p. 309).

Em Integração portuguesa nos trópicos, ${ }^{28}$ Freyre (1966, p.73), afirma que a superação da "condição étnica pela cultural caracteriza a civilização luso-tropical”. A mesma tese continuou presente nos ensaios publicados em $O$ luso e o trópico: "Miscigenação acompanhada de interpenetração de culturas. Integração em seu sentido mais amplo" (Freyre, 1961, p. 53). A civilização luso-tropical seria, enfim, antes, um processo do que um todo rígido: "Homogêneo em suas formas principais de organização e de cultura. Uno pela sua língua supranacional. Mas vário pelas linguagens nacionais e até subnacionais" (Freyre, 1961, p. 79). O agente responsável por todo esse processo era, é claro, o luso e sua capacidade de assimilação, aparentemente infinita. quanto aos debates eugenistas, esses últimos muito próximos dos ideais de branqueamento apresentados por muitos como o norte da política imigratória brasileira. Já o conceito de civilização, remetendo à ideia de cultura e de interações sociais, trazia à tona a hipótese de des${ }^{28}$ Nessa edição de 1966, o texto aparece como "apenso". tinos e tradições supostamente comuns. Como assinala Palhares-Burke (2005), apoiando-se em Skidimore (1999), Freyre havia aprendido com Boas e com intelectuais brasileiros, como Roquette-Pinto, ${ }^{29}$ a diferenciar raça e cultura. Eventualmente, raça e cultura poderiam estar mescladas, mas não a favor de qualquer tipo de hierarquia racial. Ao insistir, após a viagem ao estado gaúcho, no "abrasileiramento" de alemães e italianos no sul do Brasil, Freyre tanto se oporia às teses raciais quanto reforçaria as qualidades assimiladoras da formação luso-tropical. Assim fazendo, contudo, Freyre rompe (in)conscientemente com a questão central dos estudos migratórios: o debate em torno da hierarquia entre quem assimila e quem é assimilado; entre a sociedade de origem e a sociedade hospedeira. No caso luso, ambas, inicialmente distintas, findariam por estabelecer interações sociais em nível de igualdade, porque originárias da mesma unidade civilizacional. Como assinalou Green (2006), essa unidade analítica não teria grande posteridade dentro dos estudos sobre imigração, seja nas ciências sociais, seja na história. Foi, porém, a perspectiva adotada por Freyre. Devido ao partido teórico escolhido - afastar-se da unidade indivíduo e adotar a unidade de análise civilização luso-tropical, ${ }^{30}$ criada especialmente para esse fim - a contribuição freyriana para os estudos migratórios ficou ali parcialmente obscurecida. Mas, afora a experiência gaúcha, onde mais teria Freyre buscado evidências empíricas para afirmar essa civilização?

\section{O LUSO-TROPICALISMO EM QUESTÃO}

O luso-tropicalismo freyriano foi objeto de inúmeras análises, tanto no Brasil quanto no ex-

${ }^{29}$ Sobre a importância de Roquette-Pinto para os debates imigrantistas no Brasil e sua oposição à política de branqueamento, ver Stepan (2005) e Lima \& Sá (2008).

${ }^{30}$ Seria possível ver nessa noção de Civilização luso-tropical fenômeno próximo aos atuais debates sobre o transnacionalismo? Fica o registro e o convite para outras pesquisas. 
terior (Cabaço, 2007; Cabral, 2010; Castelo, 1999, 2011; Conceição Neto, 1997; Medina, 2000; Ribeiro, 2001; Dávila, 2011; Schneider, 2012). As interpretações variam. As críticas ao luso-tropicalismo, realizadas antes da viagem às colônias portuguesas, são diferentes daquelas produzidas em período posterior, quando se reconhece o apoio ambíguo do mestre pernambucano à política colonialista portuguesa. O caráter literário do luso-tropicalismo está presente em O mundo que o português criou, já analisado. Para esse, vale a crítica à inconsistência das evidências, prática científica que Skidmore (1999) identifica também em Casa Grande \& Senzala. Schneider (2012, p. 82) afirma que $O$ mundo que o português criou é, contudo, inferior a este "[...] porque repete a tese de Casa-grande e Senzala, mas sem a sofisticação analítica e empírica do livro de 1933".

Segundo Arenas (2010),

[...] a teoria luso-tropical ganha corpo e nome próprio a partir do périplo realizado por Freyre a Portugal e a diversos territórios do ultramar português (e não só) entre 1951-52, amplamente documentado no seu 'diário de bordo' intitulado 'Aventura e rotina’ (1953). Esta viagem suscitou igualmente a publicação de uma série de obras, hoje em dia pouco lidas, sendo pelo menos duas delas encomendadas pelo governo português, pretendendo ampliar e até 'stematizar' os seus pressupostos teóricos (ver Um brasileiro em terras portuguesas [1953] já mencionado, 'Integração portuguesa nos trópicos’ [1958] e ‘O luso e o trópico’ [1961]).

Ao final dessa viagem, empreendida entre fins de 1951 e 1952, surgia, assim, o luso-tropicalismo engajado, fruto de "fase propagandista”, quando Freyre teria usado e se deixado usar pelo regime salazarista (Cabaço, 2007). Castelo (1999) afirma, de forma nuançada, que o estudo do luso-tropicalismo de Freyre teria sido imposto pelo Ministério dos Negócios Estrangeiros português. Dávila (2011) acredita que, depois das severas críticas recebidas à sua obra e à sua tese da plasticidade do homem português, esse segundo luso-tropicalismo funciona, sobretudo, como uma espécie de ponte entre dois países egressos de regimes fortes, Brasil e Portugal. Conceição Neto (1997, p. 330-331) acentua a "cegueira e a incapacidade analítica de Freyre em África, dificilmente explicáveis" e a desilusão causada em africanos nacionalistas. Segundo Castelo (2011, p. 269-270):

[...] a civilização que Gilberto Freyre descreve e interpreta não existe, é antes uma aspiração, um destino. Ancorando-a em pressupostos psicológicos e históricos, o autor vai nos falando das suas características, para no fim agendar a sua plena concretização para os próximos decênios. A "integração" inscrita no título do livro de 1958 refere-se ao processo simbiótico, iniciado no século XV, de união dos portugueses com os trópicos, ou melhor, de fusão, sob a égide de Portugal, de elementos diversos, em termos geográficos, biológicos e culturais, numa nova civilização, a civilização luso-tropical.

A transposição do modelo de explicação da sociedade brasileira para os países africanos parece ter sido feita de maneira linear, sem a necessária pesquisa bibliográfica e consulta aos documentos existentes. Segundo Medina (2000), citando Andrade, ${ }^{31}$ não teria havido miscigenação nas colônias portuguesas em África. Como prova, afirma que a população de "assimilados" ${ }^{2}$ era de apenas 4.349 habitantes, para uma população portuguesa de 15.599 habitantes, números insignificantes em relação à população angolana total de 5.732.317 habitantes (dados do censo de 1955). Com base nesses números, era possível afirmar, como o faz Pinto (apud Medina, 2000, p. 53-54) que: "Se a luso-tropicalidade não explicava inteiramente a formação e a originalidade do Brasil, ela seria ainda mais falsa quando transposta para os casos dos países africanos colonizados pelos lusos.”

Nesse mesmo registro, Castelo (2011, p. 270) afirma que "[...] o que caracteriza essa civilização é uma superação da condição étnica

${ }^{31}$ Trata-se aqui de um artigo publicado em 1955 na revista Présence Africaine, por Mário de Andrade Pinto, aliás, Buanga Fele, escritor e intelectual angolano.

32 Segundo o estatuto em vigor em Angola, o "assimilado" só seria assim considerado se falasse correntemente o português e tivesse cursado a escola secundária ou a escola comercial (Medina, 2000, p. 53). 
pela cultural”. Mas, fundamentalmente, a "civilização não existe”. É “uma aspiração”. Com efeito, o projeto ou o desejo ("aspiração") de Freyre fê-lo esquecer dos elementos que deveriam compor sua imaginada civilização. Não há menção às unidades, ou seja, aos grupos étnicos (portugueses, autóctones africanos, escravos, imigrantes...) que compunham a civilização. Talvez porque esses grupos findariam por ser "superados". Assim, interessava somente explicar as relações sociais, pretensamente harmoniosas, que formavam a nova cultura e a inusitada civilização. Resumindo: há consenso em relação ao paradoxal apoio que teria feito Freyre ao colonialismo português, justamente quando sopravam ventos de liberdade entre as antigas colônias em África. Da mesma forma, sobram reparos ao teor jornalístico e superficial (sobretudo para um antropólogo) presente nas considerações sobre a África portuguesa.

A construção do conceito de Civilização luso-tropical em Freyre teria ocorrido, então, em dois tempos, antes e depois das viagens às colônias portuguesas; antes e depois da experiência parlamentar. Em ambos, contudo, o fio condutor foi a tese da "combinação de diversidade com unidade", em proveito da segunda. A ideia de unidade teve por objetivo consolidar a supremacia lusa no Brasil, ou seja, tropicalizada. A ideia de não deixar espaços para idenثิ tidades múltiplas, multiculturais, hifenizadas 凶ં ou negociadas, segundo expressão de Lesser (2000), fazia sentido no Brasil, aparentemente i ameaçado pelo estrangeirismo imigrante? Para o público pátrio, Freyre nunca teria se desviais do do partido pré-concebido: todo e qualquer $\therefore$ imigrante deveria ser compreendido como ator e reafirma a unidade analítica $\mathrm{Cl}^{-}$ vilização, e não como aquele que a fragmenta ou põe em cheque a dominância luso-tropical. O fenômeno da imigração tornou-se, assim, negativamente válido. Foi argumento inverso e não evidência crítica do multiculturalismo brasileiro. Por isso, era secundário compreender a imigração, etnológica ou demograficamente. Suas observações sobre o imigrante não tiveram outra função senão legitimar o imaginado luso-tropicalismo.

\section{PALAVRAS FINAIS}

Como dito, no livro Sociologia (1957), nos três capítulos dedicados às "sociologias especiais”, ${ }^{33}$ não há um único tópico específico dedicado à questão da imigração. Os conceitos centrais da sociologia para tratar o fenômeno da imigração - assimilação e aculturação - estão igualmente ausentes do primeiro capítulo, intitulado "Limites da Sociologia" e também do último, intitulado simplesmente "Sociologia”. ${ }^{34}$ No índice de assuntos, derradeira ausência. Contudo, no índice onomástico, personagens como William Thomas e Florian Znaniecki, autores do clássico The Polish Peasant in Europe and America, estão devidamente citados tanto quanto seus conceitos "situações" e "atitudes". ${ }^{35}$

Bastos (2006, p.166) afirma que a trilogia interpenetração etnias e cultura, patriarcado e trópico são uma chave de leitura para se compreender a obra de Freyre. Dessa trilogia, o item interpenetração etnias e cultura apresenta interfaces evidentes com o par imigração e assimilação. Seyferth (2003, p. 171) concorda: "O tema da interpenetração supõe penetração recíproca, conforme registram os dicionários, porém é usada de forma um tanto ambígua, muito mais próxima do ideal de absorção ou assimilação pela cultura dominante luso-brasileira que unifica!” Mas, se a cultura imigrante é absorvida, não colocando, assim, em xeque o domínio da civilização luso-tropical, por que a sensação de ameaça reiteradamente repetida? Apenas o contexto da Segunda Guerra explica isso? No discurso proferido durante a

${ }^{33}$ Da mesma forma, em "Problemas Brasileiros de Antropologia”, não há referências diretas ao fenômeno da imigração, mas apenas referências esparsas.

${ }^{34}$ Nesses capítulos, encontramos referências aos “contatos sociais" entre "diversas etnias", ou entre "brancos e pretos” (Freyre, 1957, p. 172).

${ }^{35}$ Autores citados na "Introdução" do livro. 
Constituinte, há uma possível resposta. Existem imigrantes e existe o português, cidadão não estrangeiro, porque luso-tropical. A diferenciação e particularização do mundo luso frente a outros caracteriza, em parte, o sentido dos estudos migratórios em Freyre. Não se tratava de assimilar indivíduos, mas civilizações. Bastos tem, de fato, razão em sua chave de leitura acima exposta. Acrescento, porém: a chave analítica "interpenetração etnias e cultura" encobre a explicação migratória.

Os pequenos trabalhos escritos após a viagem ao Rio Grande do Sul, publicados após Casa Grande \& Senzala e Sobrados \& Mucambos, são, a esse respeito, esclarecedores. Encontram-se, neles, a tese da capacidade assimiladora da cultura lusa em exemplos (a questão do hibridismo linguístico, por exemplo) bem mais detalhados do que aqueles retirados das visitas aos países africanos. Da mesma forma, lá estão analisados, teórica e empiricamente, os processos de assimilação do imigrante.

Freyre não é um sociólogo da imigração. Não há dúvida nisso. Contudo, o fenômeno da imigração não está ausente de sua obra. É possível pensar que o tema o incomodou e o inspirou. A demonstração disso pode estar no uso quase intercambiável que operou entre os termos cultura e indivíduo, tomando-os como elementos de ligação entre a ideia de civilização luso-tropical e os escritos sobre imigração. A civilização apontava para o amálgama constante que a colonização portuguesa teria realizado. Afirmar que os imigrantes europeus não portugueses haviam sido (ou estavam sendo) assimilados era comprovar a existência e o modus operandi da civilização luso-tropical. Em consequência, pode-se afirmar que tanto seus escritos sobre os imigrantes europeus quanto sobre as práticas assimilacionistas no mundo luso-tropical são importantes contribuições à sociologia da imigração, mormente no Brasil.

Recebido para publicação em 11 de fevereiro de 2016 Aceito em 05 de outubro de 2017

\section{REFERÊNCIAS}

ARENAS, F. Reverberações luso-tropicais: Gilberto Freyre em Africa. Buala, [S.l.], 2010. Disponível em < http://www. buala.org/pt/a-ler/reverberacoes-lusotropicais-gilbertofreyre-em-africa>. Acesso em: 5 jun. 2015.

ARRUDA, M. Al do N. A temática regional: considerações historiográficas. Anais do Museu Paulista, São Paulo, t. 35, p. 156-166, 1986-1987.

BASTOS, É. R. As criaturas de Prometeu: Gilberto Freyre e a formação da sociedade brasileira. São Paulo: Global: Recife: Fundação Gilberto Freyre, 2006.

BRAGA, S. S. Quem foi quem na Assembleia Constituinte de 1946: um perfil socioeconômico e regional da constituinte de 1946. Brasília, DF: Câmara dos Deputados, 1998. 2 v.

BURKE, P.; PALHARES-BURKE, M. L. G. Repensando os trópicos: um retrato intelectual de Gilberto Freyre. São Paulo: Ed. Unesp, 2009.

CABACO, J. L. de O. Moçambique: identidades, colonialismo e libertacão. 2007. 475 f. Tese (Doutorado em Antropologia Social) - Faculdade de Filosofia, Letras e Ciências Humanas, Universidade de São Paulo, São Paulo, 2007.

CABRAL, T. P. O luso tropicalismo: reflexões sobre a cultura política luso-brasileira. 2010. 135 f. Dissertação (Mestrado em Relações Internacionais e Ciencia Poítica) - Faculdade de Ciências Sociais e Humanas, Universidade Nova de Lisboa, Lisboa, 2010.

CÂMARA, A. de L. Os alemães no Sul do Brasil - ponto de vista brasileiro. Revista de Imigração e Colonização, Rio de Janeiro, ano I, n. 1, p. 33-46, 1940.

CÂMARA, A. de L.; NEIVA, A. H. Colonizações nipônica e germânica no sul do Brasil. Revista de Imigração e Colonização, Rio de Janeiro, ano 2, n. 1, p. 39-119, 1941.

CASTELO, C. O modo português de estar no mundo: o luso-tropicalismo e a ideologia colonial portuguesa: 19331961. Porto: Afrontamento, 1999.

CASTELO, C. Uma incursão no luso-tropicalismo de Gilberto Freyre. Blogue de História Lusófona, Lisboa, ano 6, 2011. Disponível em < http://www2.iict.pt/archive/doc/ bHL Ano VI 16 Claudia Castelo Uma incursao no lusotropicalismo.p.p df > . Acēsso em: $\overline{3}$ mar. $\overline{2} 015$.

CHACON, V. Discursos parlamentares/Gilberto Freyre: seleção, introdução e comentários de Vamireh Chacon. Brasília, DF: Câmara dos Deputados, Coordenação de Publicações, 1994.

CONCEIÇÃO NETO, M. da. Ideologias, contradições e mistificações da colonização de Angola no século XX. Lusotopie, [S.1.], p. 327-259, 1997.

DÁVILA, J. Hotel trópico: o Brasil e os desafios da descolonização africana, 1950-1980. São Paulo: Paz e Terra, 2011 .

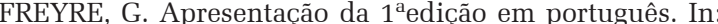
OBERACKER JR, C. H. A contribuição teuta à formação da nação brasileira. 4. ed. Rio de Janeiro: Presença, 1985. v. 1, p. 13-17.

FREYRE, G. Aventura e rotina: sugestões de uma viagem à procura das constantes portuguesas de carácter e ação. 2 . ed. Rio de Janeiro: Livraria José Olympio, 1980a. (Coleção Documentos Brasileiros, n. 77).

FREYRE, G. Continente e Ilha. Rio de Janeiro: Edição da Casa do Estudante do Brasil, 1943.

FREYRE, G. Entrevista concedida a Arnon de Mello. Diário de Pernambuco, Recife, 12 jan. 1942.

FREYRE, G. Integração portuguesa nos trópicos. In: FREYRE, G. Uma política transnacional de cultura para 
o Brasil de hoje. Belo Horizonte: Edições da Revista Brasileira de Estudos Políticos, 1966.

FREYRE, G. O Brasileiro entre outros hispanos: afinidades, contrastes e possíveis futuros nas suas inter-relações. Rio de Janeiro: J. Olympio, 1975.

FREYRE, G. O luso e o trópico: sugestões em torno dos métodos portugueses de integração de povos autóctones e de culturas diferentes da europeia num complexo novo de civilizacão: o luso-tropical. Lisboa: Comissão executiva das comemorações do Quinto centenário da morte do infante Dom Henrique, 1961.

FREYRE, G. O mundo que o Português criou. Rio de Janeiro: Livraria José Olympio, 1940.

FREYRE, G. Novo mundo nos trópicos. Lisboa: Livros do Brasil, 1972.

FREYRE, G. Nós e a Europa germânica: em torno de alguns aspectos das relacões do Brasil com a cultura germânica no decorrer do século XIX. 2. ed. Rio de Janeiro: Bra-Deutsch., 1987. (Documentário Teuto-Brasileiro).

FREYRE, G. Ordem e progresso: processo de desintegracão das sociedades patriarcal e semipatriarcal no Brasil sob o regime de trabalho livre: aspectos de quase meio século de transição do trabalho escravo para o trabalho livre; e da Monarquia para a República. 2. ed. Rio de Janeiro: Livraria José Olympio, 1962. 2 tomos.

FREYRE, G. Problemas brasileiros de antropologia. 4. ed. Rio de Janeiro: J. Olympio; Brasília: Instituto Nacional do Livro, 1973.

FREYRE, G. Questão de Culturas. In: FREYRE, G. Uma cultura ameaçada: a luso-brasileira. 3. ed. Recife: Gabinete Português de Leitura, 1980c. p. 61-64.

FREYRE, G. Região e tradição. Ilustrado por Cícero Dias. 2. ed. Rio de Janeiro: Gráfica Reccord Editora, 1968a.

FREYRE, G. Sobrados e mucambos: decadência do patriarcado rural no Brasil. 4. ed. Rio de Janeiro: J. Olympio, 1968b. 2 tomos

FREYRE, G. Sociologia: introdução ao estudo dos seus princípios. 2. ed. rev. e aum. Rio de Janeiro: Livraria J. Olympio, 1957.

FREYRE, G. Sugestões para o estudo histórico-social do sobrado do Rio Grande do Sul. In: FREYRE, G. Problemas brasileiros de antropologia. 4. ed. Rio de Janeiro: J. Olympio; Brasília: Instituto Nacional do Livro 1973b. p. 84-98.

亏े FREYRE, G. Uma cultura ameaçada: a luso-brasileira. 3. N. ed. aum. Recife: Gabinete Português de Leitura, 1980b.

(ิ)

FREYRE, G. Uma cultura moderna: a luso-tropical. In:

FREYRE, Gilberto. Um brasileiro em terras portuguesas.

क Rio de Janeiro: J. Olympio, 1953. p. 125-154.

œ FREYRE, G. Uma explicação. In: II Colóquio de estudos Teuto Brasileiros: trabalhos de intelectuais brasileiros

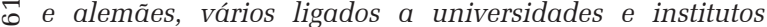
$\llcorner$ científicos dos dois países, sobre aspectos diversos da 2 matéria que motivou o Colóquio. Recife: Editora da UFPe, iे 1974, p. 11-12.

\& FREYRE, G. Uma política transnacional de cultura para o o Brasil de hoje. Belo Horizonte: Edições da Revista ค Brasileira de Estudos Políticos, 1960.

s GERTZ, R. O fascismo no sul do Brasil. Porto Alegre: Mercado Aberto, 1987.

GREEN, N. Time and the study of immigration. Rethinking क history, New York, v. 10, n. 22, p. 239-258, 2006.

KOMINSKY, E. V. LÉPINE, C.; PEIXOTO, F. A. (Org.). Gilberto Freyre em quatro tempos. Bauru: EdUSC, 2003.

LESSER, J. A negociação da identidade nacional: imigrantes, minorias e a luta pela etnicidade no Brasil. São
Paulo: Editora UNESP, 2000.

LIMA, N. T.; SÁ, D. M. de (Org.). Antropologia brasiliana: ciência e educação na obra de Edgard Roquette-Pinto. Rio de Janeiro: Fiocruz; Belo Horizonte: Ed. da UFMG, 2008.

LOPES, R. Missão no Reich: Glória e covardia dos diplomatas latino-americanos na Alemanha de Hitler. Rio de Janeiro: Lexikon Editorial Digital, 2008.

MAACK, R. The Germans of South Brazil: a German view. The Quartely Journal of Inter-American Relations, Cambridge, v. 1, n. 3, p. 5-23, 1939.

MAGAlHÃES, M. B. de. Pangermanismo e nazismo: a trajetória alemã rumo ao Brasil. Campinas: UNICAMP/ FAPESP, 1998

MCCANN JR, F. D. A aliança Brasil-Estados Unidos, 19371945. Rio de Janeiro: Biblioteca do Exército, 1995.

MEDINA, J. Freyre contestado: o luso-tropicalismo criticado nas colônias portuguesas como álibi colonial do salazarismo. Revista USP, São Paulo, n.45, p. 48-61, p. 4861,2000

MENDES, José S. R. Subsídios para um conceito sociojurídico de transnacionalidade afro-luso-brasileira. In: CARNEIRO, M. L. T.; HIRANO, S. Histórias migrantes: um mosaico de nacionalidades e múltiplas culturas. São Paulo: Humanitas, 2014. p. 323-334.

NEDEL, L. A recepção da obra de Gilberto Freyre no Rio Grande do Sul. Mana, Rio de Janeiro, v. 13, n. 1, p. 85-118, 2007.

OLIVEIRA, L. Ordem e Progresso em Gilberto Freyre. In: KOMINSKY, E. V.; LEPINE, C.; PEIXOTO, F. A. Gilberto Freyre em quatro tempos. Bauru: EDUSC, 2003, p. 135-151.

PALHARES-BURKE, M. L. Gilberto Freyre: um nordestino vitoriano. In: KOMINSKY, E. V. et al. Gilberto Freyre em quatro tempos. Bauru: EdUSC, 2003. p. 83-114.

PALHARES-BURKE, M. L. Gilberto Freyre: um vitoriano nos trópicos. São Paulo: Ed. da UNESP, 2005.

RIBEIRO, G. S. Cabras e pés-de-chumbo: o antilusitanismo na cidade do Rio de Janeiro (1870-1930). Tese (Mestrado em História - Centro de Estudos Gerais, Universidade Federal Fluminense, Niterói, 1987. Datilografado.

RIBEIRO, M. C. Venha o decreto de expulsão. A legitimação da ordem autoritária no Governo Vargas (1930-1945). São Paulo: Humanitas/FAPESP, 2012.

RIBEIRO, T. A. O luso-tropicalismo: paisagens, sentidos, identidades. In: Seminário de Tropicologia: o Brasil e o século XXI: desafios e perspectivas, 2001. Disponível em: <http://www.tropicologia.org.br/conferencia/2001luso tropicalismo.html. Acesso em 10 maio de 2015.

SEYFERTH, G. Anais do Seminário Internacional Novo Mundo nos Trópicos. Recife: Fundação Gilberto Freyre, 2000.

SEYFERTH, G. A imigração no Brasil: comentários sobre a contribuição das ciências sociais. BIB, 57, 7-47, 2004.

SEYFERTH, G. Nacionalismo e identidade étnica. Florianópolis: FCC, 1981.

SEYFERTH, G. Nacionalismo e imigracão no pensamento de Gilberto Freyre. In: KOMINSKY, E. V., LEPINE, C.; PEIXOTO, F. A. Gilberto Freyre em quatro tempos. Bauru: EdUSC, 2003. p. 155-179.

SEYFERTH, G. Os estudos da imigração no Brasil: notas sobre uma produção multidisciplinar. In: SANTOS, M. et al. Mundos em movimentos: ensaios sobre migrações. Santa Maria: Ed. UFSM, 2007. p. 103-122.

SCHNEIDER, A. L. Iberismo e lusotropicalismo na obra de Gilberto Freyre. História da historiografia, [S.l.], n. 10, 2012. p. 75-93. 
SCHULZE, F. Nation and migrations: German-speaking and Japanese Immigrants in Brazil, 1850-1945. In: FOOTE, N.; GOEBEL, M. (Ed.). Immigration and national identities in Latin America. Gainesville: University Press of Florida, 2014. p. 115-138.

SKIDMORE, T. Preto no branco: raça e nacionalidade no pensando brasileiro. São Paulo: Cia das Letras, 1999.

SILVEIRA, E. O Rio Grande do Sul visto de fora: raça e nacionalidade na passagem do século XIX ao século XX.

[200-] Disponível em: < www.klepsidra.net/lepsidra24/ racismo.html>. Acesso em: 25 jul. 2015.
STEPAN, N. L. A hora da eugenia: raça, gênero e nação na América Latina. Rio de Janeiro: Editora Fiocruz, 2005.

THOMAS, A. R. O luso-tropicalismo: paisagens, sentidos, identidades. In: SEMINÁRIO DE TROPICOLOGIA: O BRASIL E O SÉCULO XXI: DESAFIOS E PERSPECTIVAS,

35., Recife, 2001. Anais... Recife: [s.n.], 2001. Disponível em: <http://www.tropicologia.org.br/conferencia/2001luso_ tropicalismo.html >. Acesso em: 10 maio 2015. 


\section{AROUND THE LUSO-TROPICAL CIVILIZATION: Gilberto Freyre's contribution to the sociology of immigration in Brasil}

\author{
Márcio de Oliveira
}

Strictly speaking, there isn't a sociology of immigration in the works of Gilberto Freyre. Nonetheless, immigration isn't a topic absent from analyses on the freyrian model of amalgam and on social and racial miscegenation. It is present also in lectures and books on the luso-tropical civilization, and in his interest and travels through other cultures and countries. It can also be observed in his parliamentary acting in defense of lusophony during the Assembleia Constituinte [Constituent Assembly] of 1946. This paper discusses Freyre's contribution to the sociology of immigration in Brazil, with regards to a more general discussion on luso-tropicalism. Putting into a comparative perspective the definitions of luso-tropicalism and analyses of assimilation processes, the paper concludes that the studies in which Freyre analyses aspects of immigration were a decisive counterpart to the development of his ideas on the lusotropical civilization, in addition to being important contributions to the sociology of immigration in Brazil.

KEYwORDs: Gilberto Freyre. Sociology of Immigration. MотS-CLÉs: Gilberto Freyre. Sociologie del'immigration. Immigration. Assimilation. Luso-tropical civilization. Assimilation. Civilisation luso-tropicale.

\section{EN CE QUI CONCERNE LA CIVILISATION LUSO- TROPICALE: la contribution de Gilberto Freyre à la sociologie de l'immigration au Brésil}

\author{
Márcio de Oliveira
}

Il est certain qu'il n'y a pas de sociologie de l’immigration dans l'œuvre de Gilberto Freyre. Le phénomène de l'immigration existe cependant dans ses analyses du modèle d'amalgame et des processus de miscégénation sociale et raciale. Ce phénomène est aussi présent dans ses conférences et ses livres sur la civilisation luso-tropicale, dans son intérêt et ses voyages pour d'autres cultures et dans d'autres pays. On peut encore l'observer dans son action parlementaire pour la défense de la lusophonie lors de l'Assemblée Constituante de 1946. Cet article traite de la contribution apportée par Freyre à la sociologie de l'immigration au Brésil en ce qui concerne la discussion plus générale sur le luso-tropicalisme. La mise en perspective comparée des définitions du luso-tropicalisme et des analyses des processus d'assimilation, permet d'en arriver à la conclusion que les études dans lesquelles Freyre analyse les aspects de l'immigration furent une contrepartie décisive pour le développement de ses idées sur la civilisation luso-tropicale, sans compter les importantes contributions apportées à la sociologie de l'immigration au Brésil.

Márcio de Oliveira - Doutor em Sociologia pela Universidade de Paris V. Professor Titular do Departamento de Sociologia da Universidade Federal do Paraná. Líder do Grupo de Pesquisa "Estudos sobre Sociologia, Multiculturalismo e Migrações Internacionais”. Integra o Programa Política Migratória e Universidade Brasileira (UFPR) desenvolvendo pesquisas na área de migrações internacionais. Publicaçõe recentes: Habitus migrante e capital de mobilidade: a teoria de Pierre Bourdieu aplicada aos estudos migratórios (com Fernando Kulaitis, Revista Mediações, 2017); Visages du Brésil meridional: l'immigration polonaise et italienne au Paraná entre la fin du XIXe siècle et le début du Xxe siècle (Revue Confins, 2017); Immigrants haitiens au Brésil: du multiculturalisme à l'oeuvre? (Al Irfan, Revista de Ciencias Humanas y Sociales, 2016). 